on. Traction is to be maintained during the hardening of
the plaster. The latter takes place in about three minutes. the plaster. The latter takes place in about three minutes.
Next the limb should be laid on a large soft pillow, the toes
directed upward, and the knee a little bent. In the applicadirected upward, and the knee a little bent. In the applica-
tion of the bandage great caution should be observed that
it is not it is not drawn tightly anywhere, and that no one turn of the
bandage is tighter than another. The support is to be equal bandage is tighter than another. The support is to be equal
everywhere. The two splints should not meet by about half
an inch either down the front or back. The intervals are an inch either down the front or back. The intervals are
spanned by the dry porous muslin; at the sides the bandage
is fixed to the splints by the plister, which oozes into it from the outer layer of flannel. If it become necessary next day,
or later, to ease the splints, or to inspect the limb at any or later, to ease the splints, or to inspect the limb at any
spot, the bandage can be slit up with scissors along the mid-
dle line in front. One or both of the splints can then be de line in front. One or both of the splints can then be
eased from the limb and readjusted by the addition of another bandage. It is undesirable to wholly remove the
splints. They are hinged together at the back by the muslin
bandage which spans the interval there. The trimming of
the apparatus may be done as soon as the plaster shall have the apparatus may be done as soon as the plaster shall have
hardened. Shoulu the surgeon be short-handed with regard to assistance, he may apply the outside splint first, and lighthardened, he may put on the inside one. As swelling sub-
sides, and the splints become more or less loose, an additional bandage should be put on.
At the end of ten days, if the patient is convalescing, the outside bandage may be gummed, or a fresh gummed
bandage rolled on. That apparatus will last until splints are no longer needed. At the end of a fortnight, or three pay leave the hos This mode of treatment is admirably adapted to oblique
fractures. accompanied by displacement of the tibia, to cases
of Pott's fracture, and to comminuted fractures. of Pott's fracture, and to comminuted fractures.
Immediate Use of the Apparalus. -The splints are to be put on when the surgeon is first called to the case. Swelling
from contusion and subcutaneous laceration, uncomplicated from contusion and subcutaneous laceration, uncomplicated with lesion of the vascular trunks, is not an objection to the
immediate application of the apparatus. On the contrary, the support and enforced rest have a beneficial influence in
controlling swelling and its consequent pain. Covering the Seat of Fracture by Bandage and Splint. - I had
never observed that any benefit had been derived from the never observed that any benefit had been derived from the
old practice of leaving those parts exposed. On the con-
trary, I had thought that the swelling and vesication were aggravated by the omission to support those parts. I have the fracture has not been properly reduced, the compression
of the skin by the bone and splint will probably cause a slough. My remarks apply to those cases in which the bones
have been properly coapted. In thesecases the pain is relieved, and the swelling is modified, by the equable support
afforded by the splints and bandages. I have not hesitated to resort to them two and five days after the receipt of the
injury, when swelling, and, indeed, vesication, had already
occurred. I may particularly refer to two cases of Pott' occurred. I may particularly refer to two cases of Pott's racture, in which the dislocation had not been thoroughly
reduced. Those cases were dressed a week ago to-day, and
are now under observation. In one of them the skin over are now under observation. In one of them the skin over
the inner malleolus was already turning black. In the other the leg was swollen, red, and vesicated. The deformities were under the influence of ether, and the plaster splints back splint. which ensue when thoroughly equable light support is afforded to a broken limb. It assists to make and it main-
tains extension, it prevents the recurrence of dislocation, and it obviates the irregular spasmodic muscular movements which occur to an imperfectly supported broken limb. The
old short inside and outside splints do not afford these ad-
vantitges. The limb is unevenly squeezed between the two vantiges. The limb is unevenly squeezed between the two
unyielling concave pieces of wood, or between one splint
and a barkage. Similarly, when the limb is bandaged into Liston's back splint, it suffers compression between the two
appliances. These splints are also not well adapted to main.
tain extension.

Plaster of Paris Bandages. - These are capable of insuring
all the desiderata, but I do not employ them for the followall the desiderata, but I do not employ them for the follow-
ing reasons: First, that an inexperienced bandager may create
uneven pressure by drawing one turn of the bandage tighter uneven pressure by drawing one turn of the bandage tighter
than another, or by crowding on the bandage and plaster
more thickly at one part; secondly, that if the bandage is to more thickly at one part; secondly, that if the bandage is to must be tediously cut through; thirdly, that the bandage
must be reapplied as a whole, and the limb therefore submust be reapplied as a whole, and the limb therefore sub-
jected to loss of support, remanipulation, and probably re-

The lateral splints, hinged together by muslin, present
none, or as few as possible of these risks and disidvantages. The softness and elasticity of the flannel obviate the risk
from uneven bandaging, and the span of soft muslin between from uneven bandaging, and the span of soft muslin between
the front edges of the splints can be easily cut down with ordinary scissors, as I have already pointed out

found in what is known as the "Bavarian" splint. It is, however, less easy to maintain efficient extension during the
fixation of the latter splint than it is to do so during the same process with regard to the lateral splints; but the more
serious objection is in the fact that the "Bavarian" splint serious objection is in the fact that the "Bavarian" splint must be taken off for the purpose of trimming. That step
entails upon the patient remanipulation, perhaps resetting, Starch, Water-glass, Glue, Gummed and Other Fixed Band-
ages.-These all have the ages.-These all have the objection that their drying, hard-
ening, or stiffening is a slow process. Plaster of Paris hardens in about three minutes, less or more. Splints of
this material possess as much durability as can be required,
especially when they have been protected by the addition of a gummed bandage have been protected by the addition of a gummed bandage.
When the patient is convalescent, but still needs some
support from splints, the side-splints can be taken off and support from splints, the side-splints can be taken off and
trimmed, eyelet holes can be inserted along the front edges, and the splints can be laid on or removed at will. If the
patient be restless, or become the subject of delirium tremens, the fractured limb, secure in its all-but-complete case, may be swung in the ordinary suspensory apparatus,
or may even be left free to be jerked about without much, or may even be left free to be jerked about without much,
if any, harm. Fractures near the knee-joint, and fractures
of any part of the shaft of the femur, have been successfully of any part of the shaft of the femur, have been successfully
treated with the aid of this apparatus. The pain just treated with the aid of this apparatus. The pain just
above the heel, which so commonly plagues a patient whose
leg has been complained of by those whose fractures are put up in these
plaster splints.

Adaptability to Country and Private Practice. - These splints
re characterized by their simplicity, stability, and economy, and therefore commend themselves strongly to the country
practitioner. Instead of wooden or metallic splints, which practitioner. Instead of wooden or metallic splints, which
may or may not fit, the surgeon can take out with him, to
his case, a bag of plaster of Paris and the muslin bandages but need not be the very best, must be dry, and therefore should be kept, when in store, in a dry warm place. House-
lannel does not appear to require "shrinking." The sur-
geon should be cautious in using any flannel which has not been in some way shrunk. Ordinary new flannel might
shrink on the limb and fail to yield to the swelling. - Lancet. CHEMISTRY.

"Note on the Occurrence of Dioptase on Chrysocolla from A sHort time ago Mr. W. M. Hutchings, F.C.S., of Bir-
enhead, sent me some specimens of chrysocolla (CuSiO kenhead, sent me some specimens of chrysocolla $\left(\mathrm{CuSiO}_{2}+\right.$
$2 \mathrm{H}_{2} \mathrm{O}$ ), from Peru, accompanied with a statement that there were some minute crystals in a cavity in one or two of the
pecimens which nichth possibly prove to be the rare mineral dioptase (CuSjO $\mathrm{C}_{2}+\mathrm{H}_{2} \mathrm{O}$ ). I proceeded to make a crystallo-
graphical and chemical examination of the crystals, and graphical and chemical examination of the crystals, and ognized under the microscope. The chrysocolla mass is
eaten into in one or two spots, cavities being produced, which are divided into numerous cells by the intersection of thin
partitions of chrysocolla substance. The dioptase crystals occur particularly fine in small green tufts and sheaves attached to the partition-walls of the cells, while those crys-
tals clothing the interior of the cells are not so well developed as the others. The measurements so far obtained have
not been satisfactory, owing to the extreme smalness of the crystals, but the forms observed are those peculiarly charac
teristic of dioptase, viz., $\infty \mathrm{P} 2-2 \mathrm{R}$; the rhombohedron being gremely well defined. No other forms were observed, bu a great many fine acicular sub-individuals growing parallel
with each other build up a large individual. Some of the
crystals I carefully picked out and examined chemically with the following results, viz.: Heated betore the blowpipe owing to one of two causes - either (1) the flame was not a
pure oxidizing flame, and a little of the cupric oxide was re-
unced to cuprous oxide; or (2) there was a slight ad nixture of quartz with the dioptase crystals. The presence of cop-
per was' proved by dissolving a crystal in a drop of hydro per was' proved by dissolving a crystal in a a drop of hydro-
chloric acid, evaporating off the latter, re-dissolving the residue in a drop of acetic acid and adding potassium ferrocyaThere was not the slightest effervescence on dissolving the
mineral in hydrochloric acid, but flocculent particles of silica separated out. Mr. Hutchings obtained identical results in a chemical examination of the crystals. From the above tests

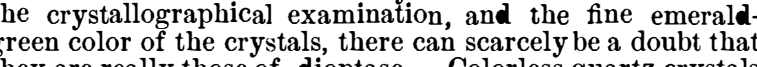
they are really those of dioptase. Colorless quartz crystals
were also observed associated here and there with the diopwere, but $+R$ and $-R$ were both present, generally nearly
in equilibrium, and the prism faces exhibited strongly the characteristic horizontal striation; therefore, coupling the the two minerals in could scarcely be possible.
I believe this is the first instance

I believe this is the first instance ohserved of dioptase oc-
curring simultaneously with chrysocolla, and according to my knowledge the first time it has been found in Peru-in act, out of Russia. The exact locality of the mine cannot
unfortunately be ascertained. I am of opinion that the dioptase has been formed by the action of water upon the chrys-
ocolla, the latter being a product of the decomposition cuprite (which is always intimately associated with it) by a chite sometimes occurs associated with chrysocolla and cu.
prite in the same locality in Peru. I hope shortly to obtain "On Indigo-blue from .Polygonum tinctorium and other
"Onts. Plants," by EDWARD SCHUNCK, Ph.D., F. R.S.
ThE author after referring to his investigation of Isatis
inctoria, the common woad plant, the results of which were communicated to the Society many years ago (Memoirs, 2d communicated to the Society many years ago (Memoirs, 2
series, xii., p. 177, and xiv., p. 181), proceeded to give an ac-
count of some experiments he had recently made with Polygonum tinctorium, a plant employed by the Chinese for the manufacture of indigo, his object being to ascertain whether
the coloring matter is contained in this plant in the same form
as in the Isatis, viz., as a glucoside. His experiments led to he conclusion that the leaves of P. tinctorium contain a substance which cannot be dis' inguished from the indican of the woad plant. It is amorphous, soluble in water, alcohol,
and ether, and by the action of acids is decomposed into in digo-blue and a substance giving the reaction of glucose,
probably indiglucine. When its watery solution is boiled or probably indiglucine. When its watery solution is boiled or
left to stand for some time, it undergoes a complete change,
and then no longer yields indigo blue by decomposition with acids, but indigor red and other products, indican, as formerThe author recommends for the preparation of this sub-
The authos The author recommends for the preparation of this sub stance the following process: The leaves of the plant having
been carefully dried are ground to powder and extracted
with spirits of wine. The green alcoholic extract is evaporated at the ordinary temperature, a current of air being employed to assist evaporation. After evaporation of the alco-
hol there is left a brown watery liquid, which is filtered from
the deposited chlorophyl and fatty matters, and mixed with
acetate of lead solution. This gives a copious dirty yellow acetate of lead solution. This gives a copious dirty yellow
precipitate, which is filtered off. Basic lead acetate added is filtered off, washed with water, then with alcohol, and hen suspended in absolute alcohol. On passing a current of
carbonic acid gas through the liquid the precipitate is de-
composed, yielding lead carbonate, while the liquid acquire a yellow color. The filtrate is evaporated in a current of
air, and water is added to the residue, which it dissolves for air, and water is added to the residue, which it dissolves for
the most part. Sulphureted bydrogen is passed through Sulphureted bydrogen is passed through
the most part. after filtration is again evaporated. The residue is treated
with ether, which leaves a portion undissolved. The ethereal solution leaves on evaporation a yel
due having all the properties of indican.

The author made some experiments with the fresh leave
of the plant, from which he concludes that the leaf-cells con of the plant, from which he concludes that the leaf-cells con chlorophyl, and that the indigo-blue which is formed when
the vitality of the cells is destroyed by extreme cold, organi the vitality of the cells is destroyed by extreme cold, organic
lesion, or chemical re-agents is produced by the decompoinfluence of the living cell is removed
It has long been known that some orchidaceous plants, such
as Bletia Tankervillive and Callanthe veratrifolia, yield indigo. blue. The author examined the leaves of the former plant, he is consequently inclined to suppose that the latter will be
found in all cases to be the source from which indigo blue is The author mentions a fact which he thinks may be of inOn one occasion an alcoholic extract of do dried woad leaves,
in which the indican had undergone partial dccomposition by long standing, yielded on evaporation a quantity of a properties of tyrosine. Though it is possible that the tyro-
sine may have pre-existed in the plant, the author is inclined o think that, like the leucine previously discovered by him it was a product of decomposition of indican under condiconnection is supposed by chemists to exist between tyrosine
and indigo-blue; and on the other hand, tyrosine and leucine and indigo-blue; and on the other hand, tyrosine and leucine
so frequently occur together as products of decomposition of

"Note on the Action of Iodine Trichloride upon Carbon Bi"ulphide," by J. B. HANNAT, F.R.S.E., F.C.S.
IT is stated by Weber that when iodine trichloride is addhave examined the action of these two substances upon each have examined the action of these two substances upon each
other, and find it is according to the following equation: $2 \mathrm{CS}_{2}+3 \mathrm{AlCl} y=\mathrm{CCl}_{4}+\mathrm{CSCl}_{2}+38 \mathrm{CI}+3 \mathrm{II}$.
On adding carbon bisulphide to pure iodine trichloride till it was all decomposed considerable heat was evolved, and on of the liquid showed the presence of sulithur chloride in large quantities, and on decomposing this with water, the charac-
teristic smell of the sulpho-chloride of carbon was observed. This was further recognized by its deportment with alkalies carbon was easily recognized by its peculiar sweet smell, A weighed portion of the trichloride was heated with the
angly remidling one of the smell of primrose leaves requisite amount of carbon bisulphide to convert it into the
above products, when it was found there was neither an exabove products, when it was found there was neither an ex
cess of carbon bisulphide nor of the trichloride present. The licquid was allowed to cool, and when all the iodine had crys-
1. allized out it was passed through a small filter of asbestos, and washed with a few drops of carbon tetrachloride. The
iodine on the filter was estimated, and gave only a little under the required amount. The filtrate was then treated with weighed after transference to a tared bulb. The sulphur in was oxidized by means of potassium chlorate and of carbon as oxidized by means of potassium chlorate and strong ni-
tric acid, and estimated as barium sulphate.
The following table gives the figures which were obtained The following table gives the figures which were obtained
on working with 10 grms. of iodine trichloride, and also

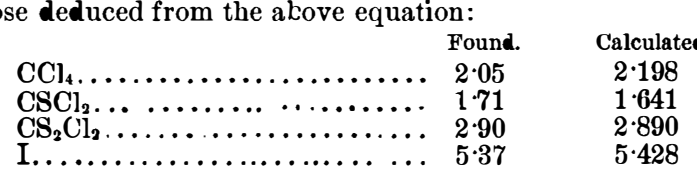

-Manchester Lit. and Phil. Soc., Chemical Newos.

ELECTRIC DISCHARGE IN TUBES CONTAINING RAREFIED GASES.

By MM. Warren de la Rue and Hugo W. Müller.

THE discharge in a tube of rarefied gas does not differ from that which takes place in air or other gases at the at-
mospheric pressure. It is not a current in the ordinary mospheric pressure. It is not a current in the ordinary
sense of the term, but a disruptive discharge, the gaseous molecules effecting a transport of electrization. The gases
probably receive two impulsions in opposite directions, that from the negative electrode being the more continuous.
There are sometimes formed metallic spots upon the tubes, which leave a permanent trace of the intervals comprised SOLUTION OF PLATINUM IN SULPHURIC ACID. By M. ScheUrer-Kestner.

IN a former communication (Comptes Rendus, lxxxi., p. 892) the author has shown that during the industrial concen-
tration of sulphuric acid in vessels of platinum the quantity f this metal dissolved in acid free from nitrous compound ments undertaken for the purpose of preparing fuming sulphuric acid have induced him to continue his observa-
tions. The action upon the metal, so much promoted by concentration beyond 95 per cent., is still further intensified
with the concentration of the monohydrated acid. On decomposing sodium bisulphate hy heat in earthen retorts lined
with platinum, 1 grm. of metal was dissolved for each kilo. tate mixed with the sodium sulphate.

ON VITREOUS MELTED SACCHAROSE. By H. Morin.

IF heated with water under certain conditions saccharose transformed into a vitreous product, which preserves its
ransparency more or less according to the manner of cooling. If this has taken place gradually the product is trans.
lucid, but mixed with prismatic crystals. If the cooling is apid this partial crystallization is avoided. It contains on
n average 3.28 per cent. of water, and its sp. gr, at $14.5^{\circ}$ is 1.966 .

\section{A NEW METHOD OF PREPARING PROPYL-} GLYCOL.

By M. Hanriot.

THE author employs aceto-brom-hydrine, which is easily prepared by the action of acetyl bromide upon glycerine.
The product of the reaction is distilled in a vacuum, and 10 centimeters of mercury. The hydrogenization is con-
ducted in a neutral liquid by means of Dr. Gladstone's copducted in a neutral liquid by means of Dr. Gladstone's cop-
pered zinc, and is completed in about twenty-four hours. The product when hot is mixed with carbonate of potassa
in excess, and the paste is exhausted with alcohol. The acetate of propyl-glycol, saponified
of potassa, yields isopropyl-glycol. 